\title{
Research on the Connotation and Operation Mechanism of Smart Exhibition
}

\author{
LI GAN $^{1}$ \\ ${ }^{1}$ College of Tourism and Aviation Services, Guizhou Minzu University, Guiyang, Guizhou, China
}

\begin{abstract}
The current development of China's convention and exhibition economy is showing a new normal, under the background of the rapid development of information technology and the era of experience economy, the transformation and upgrading of the convention and exhibition industry will inevitably develop in the direction of informatization and intelligence, that is "smart exhibition". This article takes the theoretical research related to the development status of smart exhibition as the starting point, studies and analyzes the connotation, elements and structure of smart exhibition, discusses the basic framework of smart exhibition, reveals the operation mechanism of smart exhibition, and forms some basic viewpoints and theories about smart exhibition.
\end{abstract}

\section{INTRODUCTION}

As China's convention and exhibition economy enters a new normal, smart convention and exhibition is an important breakthrough direction for the transformation and upgrading of the traditional convention and exhibition industry. Mobile Internet, internet of things, big data, cloud computing and other information technologies provide technical support for the intelligent development of the convention and exhibition industry, which can realize the intelligent application, intelligent management and intelligent service of convention and exhibition activities, and break the space-time limitation of traditional convention and exhibition activities, to raise the service quality and operation level of MICE to a new height. In recent years, China has successively issued promotion policies to encourage the intelligent upgrading of the exhibition industry. For example, in 2015, the State Council issued "Several Opinions on Further Promoting the Reform and Development of the Exhibition Industry", which pointed out that "accelerating the transformation and upgrading of the exhibition industry, promoting cloud computing, big data, internet of things, mobile internet, etc. in the exhibition industry." Many cities have also issued plans and programs for the construction of smart cities, which provides a background basis for smart exhibitions and smart services of exhibitions. After the global outbreak of the Novel coronavirus pneumonia in 2020, it has had a huge impact on the development of the convention and exhibition industry, but the industry development and epidemic situation are accelerating the disruptive and intelligent upgrade of the convention and exhibition industry. The "double line" exhibition will become the development of the convention and exhibition industry in the future. Trends in the future will be a critical period for the upgrading of smart services in the convention and exhibition industry.

\section{Research Overview}

In 2008, IBM first proposed the concept of "smart earth", its main content is to fully apply information technology to various industries to form the internet of things, and then connect the internet with the internet of things through supercomputers and cloud computing performs advanced calculations and accurate presentations on the large amounts of data collected, enabling humans to more efficiently manage production and life, thereby bringing the world to a "smart" state[1]. Smart earth has six smart solutions: smart city, smart transportation, smart power, smart medical care, smart finance, and smart supply chain, of which smart city has a leading role and lays the foundation for the development of smart exhibition.

\subsection{Foreign Research Status}

The concept of smart exhibition comes from "smart earth" put forward by IBM in 2008 and its widely used practice achievement - "smart city". Since 2008, based on the relevant theory and practice research results of smart industry, foreign scholars have begun to study the intelligence and informatization of the exhibition industry. From the perspective of theoretical research, although there are few theoretical studies abroad, some scholars have begun to systematically study the application and related concept system of smart exhibition. Robert G. Holland created and reflected on the application of smart city in the future after the concept of smart earth was proposed, which established a theoretical framework for the systematic research of smart exhibition[2]. Warwick Neville made an depth study on Singapore, a leading 
country in smart city construction, and mentioned the role of smart city in the management and operation of convention and exhibition events, which is an extension of the research results of smart city in the exhibition industry. Hyeon Kim and other scholars discussed the application of internet, internet of things, infrared ray, GPS and other technologies in smart exhibition service, this is the first time that foreign scholars put forward the concept of smart exhibition. Through sorting out the relevant research achievements of smart exhibitions abroad, it is found that there is a lack of theoretical research on smart exhibitions abroad, most of the relevant research results are focused on the practical application and technology development of information technology in exhibition venues and exhibition activities. Foreign countries pay attention to the analysis and solution of practical problems in the research of smart exhibition, and focus on mining the application of smart exhibition and informatization in convention and exhibition activities, technology development, and informatization of enterprise management, there are few pure theoretical studies, mostly case studies, empirical research[3].

\subsection{Domestic Research Status}

Smart exhibition and other concepts belong to the extension of smart earth and smart city, which are mostly proposed by Chinese scholars or industry. As a part of the development of smart cities, smart exhibition has been included in the "13th Five-Year" construction plan in many regions of China, for example, cities such as Shanghai and Guangzhou clearly proposed that the city's "smart exhibition" as the foothold, promote the development of intelligent and standardized exhibition industry. Although the research on the concept of smart exhibition in China is still in its infancy, and the concept of smart exhibition in academia has not been clearly unified, scholars have described the concept of smart exhibition. Smart tourism is the extension of smart earth and smart city, in recent years, Chinese academic circles have made some achievements in the study of smart tourism, some scholars have applied the theory of smart tourism to the field of exhibition and proposed that smart tourism can improve the experience of exhibitors and visitors in exhibition activities. Convention and Exhibition informatization is usually considered as the primary form of smart exhibition, with the deepening of research and the progress of information technology, the technology fields involved in smart earth, smart city, smart tourism and smart exhibition defined in China are also expanding, from internet of things and mobile communication technology to cloud computing, artificial intelligence, big data, etc., and exhibition informatization and TCT technology in recent years, academic circles have paid more and more attention to its application in exhibition activities. Although China's convention and exhibition industry has gradually realized the technology exploration and market application in the field of smart exhibition, the theoretical research on smart exhibition is still in its infancy, and there is no unified and recognized view on the concept of smart exhibition in the industry and academia.
In summary, although there is currently no mature and systematic theoretical research on smart exhibition in domestic and foreign academic circles, the development of the smart industry is only about 10 years, with the passage of time, the continuous progress of technology and application, the research on smart exhibition will become more and more mature and form a perfect theoretical system.

\section{Connotation Analysis of Smart Exhibition}

\subsection{Origin of the Concept of Smart Exhibition}

The concept of smart exhibition originates from "smart city", which is the expansion of "smart city" in its element field. The word "smart" is literally interpreted as the intelligence and application ability of cognition, response and innovation of things, smart has different etymology at home and abroad. In China, "smart" has appeared in the ancient Warring States period, meaning intelligence. In Wikipedia, "smart" is an adjective used to describe people or animals with high intelligence, and is widely used as an adjective in the fields of products, engineering, technology, commerce, social undertakings, etc. In 1972, the word "smart" was first interpreted as "intelligent, with independent technical equipment". Subsequently, "smart" is gradually used in urban context to reflect a successful urban development policy. "Smart city" is gradually used to describe an urban development model based on information technology to promote urban innovative operation. "Smart" reflects all technology-based urban innovation behaviors in urban planning, development and operation. From the analysis of the origin and evolution of " smart " at home and abroad, we can see that "smart" mainly has two meanings: one is the cognition of things, the other is the ability to apply things, both of them have the characteristics of innovation and wisdom. As a new concept in the theoretical and industrial circles, analyzing the source of "smart exhibition" is the starting point of understanding smart exhibition. from the perspective of concept source, "smart exhibition" represents a solution to realize its own innovation and development based on information technology. this scheme provides basic ideas for the optimization and development of exhibition operation system.

\subsection{The Concept of Smart Exhibition}

With the continuous development of the exhibition industry, the exhibition industry has completed the upgrading of "original exhibition-traditional exhibitiondigital exhibition-intelligent exhibition". It is the inevitable product of the continuous development and evolution of social and economic forms. It benefits from the influence of production behavior, consumption behavior and other factors, and can reflect the characteristics of the times under the background of experience economy. The "smart" in smart exhibition represents the perfect combination of advanced and 
intelligent information technology and human intelligence with the development of the exhibition industry, promoting the efficient utilization and optimal allocation of core resources in the exhibition industry, so as to make the stakeholders of the exhibition have a good exhibition experience. "Smart Exhibition" can be divided into broad sense and narrow sense.

In a broad sense, smart exhibition refers to a more efficient, convenient, innovative and personalized exhibition experience, through the intelligent management means and technology application, the intelligent management, information integration and resource sharing of each subject of the exhibition can be realized, so that the whole exhibition system can be connected with each other to provide higher benefits for the exhibitors, it is a new exhibition form.

In a narrow sense, smart exhibition refers to the application of smart technology in all aspects of the exhibition based on information and communication technology, so as to coordinate the operation of all aspects of the exhibition and provide intelligent services for the exhibition subjects, it is a new exhibition service mode.

\subsection{Components of Smart Exhibition}

The exhibition industry is a producer service industry, and its practical development is ahead of the theoretical research, many scholars summarize the practical experience of the development of smart exhibition and tentatively discuss the constituent elements of smart exhibition. Smart exhibition has many elements, but technology, organization and system are the key components (Figure 1), the three are interrelated and interconnected, the development of smart exhibition must also consider the innovation of technology and the aspects of organization (person) and system. Smart exhibition is an innovation of the original development model of the exhibition industry, which will bring changes in the organization, management, operation and service mode of the exhibition industry. If we analyze the components of smart exhibition from a broader perspective, it should also include management, organization, technology, policy, people, economy, infrastructure and other elements. Among these elements, technology, organization and system have a greater impact on other elements. For smart exhibition, it is very important to explore and analyze what elements it consists of, but it is also of great theoretical and practical significance to explore the status and role of various elements and how they interact to form the whole smart exhibition[4].

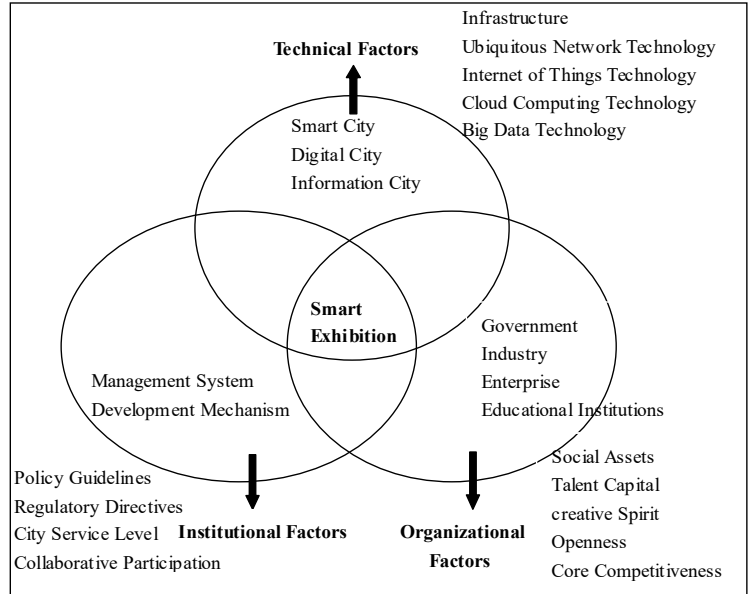

Fig1. . Components of Smart Exhibition

\section{Operation Mechanism of Smart Exhibition}

\subsection{Basic Framework of Smart Exhibition}

Smart exhibition is a system with "intelligence" characteristics, which is formed by the coupling and action of information technology intelligence, human intelligence and exhibition system. From the analysis of the constituent elements of smart exhibition, we can see that the smart exhibition system is huge and complex, but in the final analysis, it can be summarized into three stages: information collection, information transmission and processing, and practical application. Combined with the hierarchical division of the internet of things in the technical architecture, this paper thinks that the smart exhibition can be divided into three levels, namely the perception layer, the network layer and the application layer, and each level contains the corresponding technical means and requirements[5]. At the same time, each link of smart exhibition has a strong dependence on network information technology, so information security has become particularly important, which requires the development of smart exhibition must be guaranteed by policies and regulations, management system, network data security and so on. Therefore, the system framework also includes policies and regulations, standardization management and network data security management.

\subsubsection{Perceptual Layer}

The perception layer is the foundation of the whole "smart exhibition" system and the most important part of information collection. The perceptual layer can identify, analyze and record the information obtained. In the exhibition activities, the main task of the perception layer is to collect the information related to the exhibition through a series of perception equipment, and transfer the perceived information to the next stage. In exhibition activities, the spatial scope of perception layer is generally related to the scale of the exhibition, while the time range can be divided into pre exhibition, mid exhibition and post exhibition. The perception objects before the exhibition 
are mainly exhibitors and visitors. Through a series of perception devices, various information related to exhibitors and visitors are collected. The purpose of collecting these information is to make the organizers and exhibitors grasp the target market more clearly. The perception objects in the exhibition include the operation of booths, exhibits and passenger flow in the whole venue. After the exhibition, the perception objects are mainly exhibitors and visitors. The collection and analysis of information after the exhibition can feed back the effect of the exhibition, analyze the problems existing in the exhibition, and help the future market analysis.

\subsubsection{Network Layer}

The main responsibility of the network layer is to transmit the information collected by the perception layer to the server through various network means, analyze and process the information, filter the useless information, integrate the effective data, and finally transfer the processed effective data to the application layer. On the basis of information technology, the scattered information and data of individuals, enterprises, industries, organizations and government information systems are connected, interacted and shared by many parties, so as to realize the connectivity and cooperation among the stakeholders of the exhibition. The huge amount of data requires the network layer to have high-quality service and technology, and comprehensively use the existing network form to realize the "Internet of all things".

\subsubsection{Application Layer}

The ultimate goal of smart exhibition is to provide personalized and intelligent services and applications for organizers, exhibitors, visitors, venues, competent departments and other parts of the exhibition industry, as well as other peripheral services related to the exhibition. The application layer collects the final extracted effective data, and its ultimate role is to use these data to propose corresponding solutions for different service objects. The ultimate goal of smart exhibition is to build a new service mode. According to the mining and analysis of data and information, intelligent services with different levels and requirements are provided for all participants in the exhibition activities with lower cost and higher efficiency. At the same time, it is necessary to establish more diversified contact and cooperation modes among enterprises, industries, governments and other participants, so as to widely carry out the innovative application of science and technology and business in the field of convention and exhibition, and provide support for urban economic, social development and civilization progress.

\subsubsection{Security Management}

Through perception, integration, interconnection and innovative application, smart exhibition system makes full use of intelligent means from the aspects of organization, operation, management and service of convention and exhibition activities to provide timely, interactive, efficient and accurate services for all participants of exhibition activities, which can improve the operation management, comprehensive service level and core competitiveness of the exhibition industry. The development of smart exhibition should formulate a strategy suitable for China's mice economic development and construction from the national level as soon as possible, so as to ensure the construction, application and safety of smart exhibition development. Through the legislation and improvement of relevant laws and regulations on the development of smart exhibition, a complete exhibition information development system should be formed. All parties should strengthen the protection of basic data, in the case of protecting the privacy of all parties, form information protection system for individuals, enterprises and organizations, the use and protection mechanism of exhibition big data, and standardize information using behavior.

\subsection{Operation Mechanism of Smart Exhibition}

The development subject of smart exhibition is the government, exhibition organization and smart exhibition service enterprise, and the application subject is exhibitors, visitors, exhibition venues, industry associations and service enterprises related to the exhibition field, as well as non-profit institutions such as universities and scientific research institutions[6]. Through cloud computing, smart Convention and Exhibition operators can allocate platforms, software, hardware, customers and public resources connected by smart Exhibition for the purpose of service and regulation, so as to achieve the purpose of holding exhibition activities completely, improving user experience and maximizing commercial profits. Technology development is the first stage of smart exhibition operation. First of all, the government of public welfare subject gives policy support to technology development, invests resources for construction, and carries out the construction of Internet of things in the city, so as to provide a feasible basic environment for the systematic interconnection of various subjects and objects of smart exhibition. Exhibition organizations and smart exhibition service enterprises, which are profit-making entities, carry out further intelligent development in the field of convention and exhibition. Through the Internet of things, they connect the software and hardware resources of exhibition activities, and at the same time connect users through mobile communication technology, so as to collect and store the exhibition activity data, and then mine the data, so as to build a systematic and intensive online and offline exhibition people The information acquisition mechanism of objects, time and space enables the main bodies of exhibition activities to be closely connected according to their own needs[7].

\section{Conclusion}

In the process of transformation and development of the exhibition industry, the development of smart exhibition has become an irresistible development trend of the industry. Based on interdisciplinary knowledge, this paper 
first combs the research status of smart exhibition, and on this basis, puts forward the concept connotation and composition elements of smart exhibition, explores the operation mechanism of smart exhibition, and puts forward three basic principles of smart exhibition framework. Smart exhibition is based on emerging information technology to realize the operation efficiency and optimal allocation of exhibition industry resources, however, the essence of smart exhibition is to meet the needs of exhibition market customers in the era of experience economy, through the analysis and research of this paper, it can be concluded that the development of smart exhibition is the demand of transformation and upgrading of exhibition industry and supply side reform.

\section{References}

1. Joost Brinkman, "Supporting sustainability through smart infrastructures:the case of Amsterdam",Network Industries Quarterly. 2011, 13(3): 22-25.

2. Robert G. Holland, "Will the real smart city please stand up",Citie,2008, 12(3): 303-320.

3. Wang Guangbin, Cui Qinghong,Liu Huan, “Analysis and Enlightenment of Overseas Smart City Research Status",Journal of Engineering Management, 2016.

4. Zhang Xiaojuan, "Research on Elements, Institutions and Models of Smart City System", South China University of Technology Doctoral Dissertation ,2015, pp. $12-15$.

5. Jiang Chao, "Research on the design of commercial exhibitions under the trend of smart exhibitions",Nanjing Forestry University Master's dissertation, 2016, pp.31-34.

6. Zhao Junjie, "Research on the service of smart exhibition visitors based on importance-satisfaction analysis-Taking Guangzhou as an example", Guangzhou University Master's dissertation,2016, pp. 27-32.

7. Li Dan. "Research on the overall solution of wisdom exhibition construction", Value Engineering, 2019. 